IZA DP No. 4387

How Much Can We Trust Causal Interpretations of Fixed-Effects Estimators in the Context of Criminality?

David Bjerk

September 2009 


\title{
How Much Can We Trust Causal Interpretations of Fixed-Effects Estimators in the Context of Criminality?
}

\author{
David Bjerk \\ Claremont McKenna College \\ and IZA
}

\section{Discussion Paper No. 4387 \\ September 2009}

\author{
IZA \\ P.O. Box 7240 \\ 53072 Bonn \\ Germany \\ Phone: +49-228-3894-0 \\ Fax: +49-228-3894-180 \\ E-mail: iza@iza.org
}

\begin{abstract}
Any opinions expressed here are those of the author(s) and not those of IZA. Research published in this series may include views on policy, but the institute itself takes no institutional policy positions.

The Institute for the Study of Labor (IZA) in Bonn is a local and virtual international research center and a place of communication between science, politics and business. IZA is an independent nonprofit organization supported by Deutsche Post Foundation. The center is associated with the University of Bonn and offers a stimulating research environment through its international network, workshops and conferences, data service, project support, research visits and doctoral program. IZA engages in (i) original and internationally competitive research in all fields of labor economics, (ii) development of policy concepts, and (iii) dissemination of research results and concepts to the interested public.
\end{abstract}

IZA Discussion Papers often represent preliminary work and are circulated to encourage discussion. Citation of such a paper should account for its provisional character. A revised version may be available directly from the author. 
IZA Discussion Paper No. 4387

September 2009

\section{ABSTRACT}

\section{How Much Can We Trust Causal Interpretations of Fixed-Effects Estimators in the Context of Criminality?*}

Researchers are often interested in estimating the causal effect of some treatment on individual criminality. For example, two recent relatively prominent papers have attempted to estimate the respective direct effects of marriage and gang participation on individual criminal activity. One difficulty to overcome is that the treatment is often largely the product of individual choice. This issue can cloud causal interpretations of correlations between the treatment and criminality since those choosing the treatment (e.g. marriage or gang membership) may have differed in their criminality from those who did not even in the absence of the treatment. To overcome this potential for selection bias researchers have often used various forms of individual fixed-effects estimators. While such fixed-effects estimators may be an improvement on basic cross-sectional methods, they are still quite limited when it comes to uncovering a true causal effect of the treatment on individual criminality because they may fail to account for the possibility of dynamic selection. Using data from the NSLY97, I show that such dynamic selection can potentially be quite large when it comes to criminality, and may even be exacerbated when using more advanced fixed-effects methods such as Inverse Probability of Treatment Weighting (IPTW). Therefore substantial care must be taken when it comes to interpreting the results arising from fixedeffects methods.

JEL Classification: $\quad \mathrm{C} 12, \mathrm{~K} 42$

Keywords: fixed-effects, crime, marriage, gangs, smoking

Corresponding author:

David Bjerk

Robert Day School of Economics and Finance

Claremont McKenna College

313 Bauer Center North

500 E. Ninth St.

Claremont, CA 91711

USA

E-mail: David.Bjerk@claremontmckenna.edu

\footnotetext{
* Thanks to Shawn Bushway, Eric Helland, and Ray Paternoster for helpful comments and encouragement on this project. Thanks to the Lowe Institute for financial support.
} 


\section{I - Introduction}

Researchers are often interested in evaluating the extent to which criminal behavior is directly affected by specific individual characteristics, such as marital status (Blokland and Nieuwbeerta, 2005; Farrington and West, 1995; Sampson and Laub, 1990; Sampson, Laub, and Wimer, 2006; King, Massoglia, and Macmillan, 2007), gang affiliation (Gordon et al., 2004), drug use (French et al., 2000; Chaiken and Chaiken, 1990), unemployment (Farrington et al., 1986), divorce (Stolzenberg and D’Allessio, 2007), participation in school activities (Hoffman and Xu, 2002), and being in an adolescent romantic relationship (Haynie et al., 2005). Studies such as these can often be thought of as attempts to estimate the effect of a treatment (e.g. marriage, gang membership) on individual criminality. The empirical challenge to overcome in estimating such treatment effects is what is often referred to as the "missing counterfactual” problem---the researcher simply cannot observe what each treated individual's criminality would have been in the absence of receiving the treatment, or what each non-treated individual's criminality would have been if he received the treatment.

One way in which researchers have attempted to overcome this missing counterfactual problem in contexts such as these is to use different types of individual fixed-effects estimators, implicitly using each individual's behavior when not receiving the treatment as the each person's missing counterfactual. This study attempts to clearly illustrate that while such methods can solve some of the problems associated with the missing counterfactual problems, these methods can only provide truly unbiased estimates of direct causal effects of the treatment of interest on criminality under quite restrictive underlying assumptions of behavior, and moreover, when such assumptions fail, the resulting estimates can lead to very biased conclusions.

To describe the argument of this paper more specifically, first note that if some treatment characteristic of interest $x$ were randomly allocated to members of a given group, meaning that any individual characteristics that might influence individual criminality are uncorrelated with whether or not an individual receives the treatment characteristic $x$, then overcoming the missing counterfactual problem would be quite 
straightforward---one could estimate the average direct effect of the treatment characteristic $x$ on individual criminality by simply comparing the average criminality of those who received the treatment to the average criminality of those who did not, because in the absence of the treatment, the average criminality of the group receiving the treatment would have been (statistically) the same as the average criminality of the untreated group. Therefore, any difference between the two groups must be due to the treatment. In other words, under a truly random allocation of a given treatment, the untreated can act as the missing counterfactual for the treated and vice versa.

However, a key issue that arises with respect to many important criminological questions is that the allocation of the treatment is not determined completely at random. Rather, the individuals who receive the treatment characteristic $x$ at a given point in time may be systematically different than the individuals who do not, and these systematic differences may be correlated with the individual's underlying criminal tendencies at that point in time---a process often referred to as selection. This selection issue is a concern because it makes it more difficult to determine the true direct effect of the treatment characteristic $x$ on criminal behavior, because the criminality of the untreated no longer provides a valid counterfactual for the criminality of the treated and vice versa.

Numerous researchers have employed different types of fixed-effects estimators as a way to potentially overcome the selection issues discussed above in the context of criminality (examples include Horney, Osgood, and Marshall, 1995; Sampson and Laub, 1993; Osgood et al, 1996; Farrington, 1988; Nagin and Farrington, 1992a, 1992b; Grogger, 1995; Bushway, Brame, and Paternoster, 1999; Fergusson, Swain-Campbell, and Horwood, 2002; Gordon et al., 2004; Sampson, Laub, and Wimer, 2006). As alluded to previously, the underlying intuition for using fixed-effects estimators is that a given individual can act as his own counterfactual by comparing his criminal behavior before receiving the treatment to his criminal behavior while receiving the treatment. This strategy certainly addresses a major part of the selection issue---those who receive the treatment at some point in their lives may have been very different in terms of their criminality from those who never receive the treatment even if the treated had not received the treatment. 
While fixed-effects estimators can be useful in some contexts, such fixed-effects estimation strategies may still not be able to overcome potentially important selection biases in contexts where the treatment characteristic of interest $x$ is, at least partially, the product of an individual's choice. In particular, I highlight the issue of dynamic selection, where whatever causes an individual to choose to obtain some characteristic $x$ at a given point in time may also be related to changes in his underlying criminality at that point in time. Such dynamic selection will bias a fixed-effect estimate of any estimate of the direct causal effect of the treatment characteristic $x$ on criminality because it will conflate both the true treatment effect, and the effect of the whatever other changes that the individual is going through that are affecting both his underlying criminality and his choice whether or not to obtain the characteristic of interest $x$ at any point in time.

To illustrate this concern more specifically, I focus my discussion on the respective effects of gang participation and marriage on individual criminality. I focus on these two "treatments" primarily because they are not only well suited to describing the dynamic selection issues I am highlighting in this paper, but also because they have been the subjects of two relatively recent influential papers that use more innovative fixedeffects methods (Gordon et al., 2004; Sampson, Laub, and Wimer, 2006).

Consider first the issue of gang affiliation and its effect on individual criminality. An individual may transition into gang membership between one year and the next for a variety of reasons. For example, an individual may randomly meet a gang member, which then allows an opportunity for gang membership that was not previously available. If this was generally how individuals became involved in gangs, then an individual fixed-effect estimator could be used to estimate the direct effect of gang membership on individual criminality since the change that brought about gang membership at that point in time (i.e. meeting the gang member) is arguably uncorrelated with any other circumstantial or behavioral changes in the individual that might be affecting his underlying criminality. On the other hand, it could also be the case that an individual has numerous opportunities to meet gang members and/or join a gang throughout his youth, but only actively chooses to approach a gang member and join a gang at the point in time when he desires to increase his level of criminality. If this is the case for even a fraction of individuals who become gang members, then a fixed-effect estimator will overstate the impact of the 
actual gang membership on criminality, because even in the absence of being able to join a gang, these individual's criminality likely would have increased over the same time interval.

Similar issues arise when thinking about the effect of marriage on crime. Like with respect to gang membership, an individual may transition into marriage between one year and the next because he randomly encounters the "right woman" during a given time interval, giving him an opportunity for becoming married that was not available to him previously. Again, if this was the case for almost all marriages, then a fixed-effects estimator could isolate how the actual state of being married directly affects individual criminality. However, for some men, the timing of marriage may not just reflect when they met the right woman, but is a byproduct of a broader decision by these individuals that it is "time to grow up.” This decision to grow-up may cause these individuals not only to move toward building stable family lives through marriage, but also move away from committing crimes. Again, if this scenario describes even a modest fraction of marriages, a fixed-effects estimator will overstate the impact of the actual state of being married on criminality because it conflates any true direct effect of marriage on crime with the broader effects of whatever it was that prompted the individual's decision to grow up.

In general, fixed-effects type estimators can only provide an unbiased estimate of the causal effect of some individual characteristic $x$ on individual criminality if one can truly believe that the reason individuals obtain the characteristic $x$ at a given point in time is because an opportunity for obtaining that characteristic randomly arose at a given point in time that was not available previously. If on the other hand, the opportunity for some individuals to obtain characteristic $x$ was always there to some extent, and it is simply that something changes within or around the individual that causes him to choose to act on the opportunity to obtain characteristic $x$ at a given point in time, then estimated fixedeffects relationships will likely overstate the causal effect of the characteristic $x$ on individual criminality.

A key question therefore, is whether the dynamic selection biases that can arise because of individual choice, such as the ones discussed in the previous paragraphs, can be large enough that one should be skeptical of causal interpretations of even very 
significant empirical relationships found in many fixed-effects analyses? Moreover, can such dynamic selection biases be effectively minimized by more advanced fixed-effects techniques such as the before-during-after analysis performed by Gordon et al. (2004) in their analysis of gang participation on criminality, or the Inverse Probability of Treatment (IPT) Weighting done by Sampson, Laub, and Wimer (2006) in their analysis of the effects of marriage on criminality?

This paper argues that dynamic selection biases in fixed-effects analyses can potentially be very large, and moreover, can potentially be exacerbated by the more advanced techniques discussed above. In particular, using data from the National Longitudinal Survey of Youth 1997 (NLSY97), I look again at the relationships between gang affiliation and crime, and marriage and crime, using several different fixed-effects estimation approaches. Similar to the previous research cited above, I find that criminal activity increases as individuals become involved in gangs and decreases when individuals get married, and these empirical relationships become even stronger when using IPT weights.

As discussed above, these relationships can only be interpreted as purely causal if it is assumed that an opportunity to join a gang or get married arose randomly for these individuals, and it was this new opportunity that prompted each individual to join the gang or get married. The extent to which joining a gang or getting married actually reflects broader changes in some individual's attitudes or circumstances, however, may cause these estimates to be upwardly biased measures of the causal effects of these states on individual criminality.

I illustrate that such a bias can potentially be quite large when using fixed-effects approaches by also estimating the empirical relationship between smoking cigarettes and criminal behavior using the same fixed-effects methods I used to examine the relationships between marriage and gang status and crime. I argue that most individuals (even youths) always have the opportunity to be a smoker. Therefore, the time at which an individual takes up smoking reflects not a random change in his opportunity to do so, but rather must reflect a change in his attitudes or circumstances. Moreover, since I argue that it is unlikely that the act of smoking itself could directly cause an individual to commit more crime, any empirical relationship that arises in fixed-effects estimates must 
solely be due to the fact that whatever changes that an individual experienced that caused him to smoke also affected his criminal activity. Therefore, while I find a significant positive empirical relationship between smoking and crime using fixed-effects methods, this simply reveals that the dynamic selection bias can be large enough to fail to reject the false hypothesis that the act of smoking causes individuals to commit more crime. Moreover, I show that this dynamic selection bias is actually exacerbated by using more advanced fixed-effects type estimators such as before-during-after and IPTW methods.

The points made by this paper are certainly not previously unknown to researchers in the social sciences (Solon 1989; Winship and Morgan 1999; Halaby 2004). Moreover, this paper is not meant to be a pointed critique of either Gordon et al. (2004) or Sampson, Laub, and Wimer (2006) per se, as these authors clearly acknowledge the possibility that such a dynamic selection bias may be affecting their results. However, the interest these papers have stirred, and indeed the likely impetus for publishing these works in criminology's flagship journal, is arguably due to the fact that these results were viewed as primarily capturing causal effects. Therefore, while the results of this paper in no way directly imply that gang affiliation or marriage do not causally impact individual criminality, this paper is meant to re-iterate in an intuitive and relatively non-technical manner the issues of selection that can arise in fixed-effects estimation strategies. In this way, this paper is meant to more broadly push researchers using fixed-effects methods to carefully consider and discuss the underlying behavioral model they are assuming with respect to the treatment allocation and timing, and by doing so, help their readers to more fully evaluate the degree to which these assumptions are plausible and how the interpretation of empirical results would be affected should these assumptions fail.

\section{II -Attempting to Estimate Causal Relationships in the Context of Criminality}

As discussed above, an important agenda of criminological research is to understand whether the fact that an individual obtains some characteristic $x$, such as being in a gang or being married, has a direct effect on his criminality. Determining whether a given characteristic $x$ in and of itself causally affects individual criminality is extremely 
important for both evaluating different theories of crime and criminal behavior, as well as for developing effective criminal policy. In particular, if it is indeed true that obtaining or losing a characteristic $x$ affects an individual's criminality, then one important aspect of criminal policy would be to influence individual decision making regarding whether or not individuals choose to obtain this characteristic. However, if a characteristic $x$ was correlated with criminal activity, but did not actually have any causal impact on individual criminality, then policies meant to affect whether or not individuals obtain this characteristic are an inefficient use of time and resources, at least from a crime reduction perspective.

For example, if marriage truly lowers an individual's criminal proclivity, then policies that promote or otherwise facilitate marriage would be part of a comprehensive criminal policy strategy. Similarly, if gang membership truly causes individuals to drastically escalate the frequency and intensity of crime, then policies specifically focusing on breaking up and disrupting gangs will likely be a smart use of crime fighting resources. However, if the relationships between marriage and individual criminal activity, and gang participation and individual criminal activity, are not causal but simply the results of some other underlying process that results in a correlation, then the resources and policies aimed at promoting marriage and thwarting gang participation may have very little appreciable impacts on overall criminal activity.

As discussed in the introduction, in attempting to empirically identify causal links between some characteristic $x$ and individual criminality, it is often helpful to view the characteristic $x$ as a "treatment," and similarly refer to those who obtain the characteristic $x$ as "the treated." The primary difficulty in uncovering a causal link between some treatment $x$ and individual criminality then comes down to the "missing counterfactual" problem. Specifically, we simply cannot know what the actual criminality of the treated individuals would have been if they had not received the treatment.

The key to overcoming this missing counterfactual problem is to find a comparable group of individuals to the treated group who did not receive the treatment. As discussed above, if a researcher could allocate the treatment randomly among a large enough set of individuals, then this missing counterfactual problem could easily be overcome by comparing the outcomes for the treated to the outcomes for the untreated. 
However, it would be unethical and infeasible to randomly allocate many of the "treatments" of interest. For example, researchers certainly could not simply place some individuals in a gang or prevent other individuals from joining a gang. Similarly, researchers could not simply make some individuals married while preventing others from becoming married. Besides the ethical issues involved, randomly allocating such treatments simply would not be possible. Therefore, other methods are generally used to try to identify causal relationships in contexts such as these.

The most basic way to identify empirical relationships is via cross-sectional regressions. In the context of looking at what affects individual occurrences of criminal activity over a given time period, we can consider estimating a Poisson specification of the following form: ${ }^{1}$

$$
\begin{aligned}
& E\left(\text { crimes }_{i j}\right)=\eta_{i j} * \lambda_{i j} \\
& \operatorname{Ln}\left(\lambda_{i j}\right)=\beta_{j}+\beta_{T} \text { Treatment }_{i j}+\beta_{x} X_{i j}+r_{i j}
\end{aligned}
$$

where $i$ indexes individuals, $j$ indexes time period, $\eta_{i j}$ indicates number of days in time period $j$ (i.e. the length of "exposure"), $\beta_{j}$ is an intercept corresponding to each time period, Treatment $t_{i j}$ is a dummy variable indicating whether a given individual $i$ received the treatment of interest in time period $j, \beta_{T}$ is the average direct effect of the treatment on individual criminal activity, $X_{i j}$ is a vector of observable individual characteristics (e.g. age, race), $\beta_{x}$ is the vector of coefficients capturing the relationship between these characteristics and criminal activity, and $r_{i j}$ is a random individual-specific time-varying residual.

If one believed that the residual term $r_{i j}$ is truly uncorrelated with each individual's treatment status at any point in time (after controlling for the individual characteristics in $X_{i j}$ ), then one could simply estimate the above equations using standard cross-sectional regression methods to obtain an unbiased estimate of the average treatment effect $\beta_{T}$. The key concern however, is that in many if not most criminological applications there are reasons to think that the residual term $r_{i j}$ might be correlated with

\footnotetext{
${ }^{1}$ Poisson regressions are used given the dependant variable in each specification is a count variable. Negative Binomial specifications could also be used in such contexts, with an analogous discussion to the one presented here.
} 
each individual's treatment status at a point in time, causing standard cross-sectional regression methods to lead to biased estimates of $\beta_{T}$.

The most obvious reason that the residual term $r_{i j}$ might be correlated with each individual's treatment status at a point in time is the presence of some unobserved individual characteristic that impacts both an individual's criminal tendency at each point in time as well as the individual's tendency toward obtaining the treatment at any point in time. In other words, the criminality of otherwise similar individuals who don't get the treatment is not a valid counterfactual for the criminality of those who do.

To illustrate this issue more explicitly, we can re-write equation (2) as follows,

$$
\operatorname{Ln}\left(\lambda_{i j}\right)=\beta_{j}+\beta_{T} \text { Treatment }_{i j}+\beta_{x} X_{i j}+\left(\mu_{i}+\varepsilon_{i j}\right)
$$

where the residual term is now divided into two components, the individual-fixed component $\mu_{i}$, and the individual time-varying component $\varepsilon_{i j}$. Moreover, we can also formally recognize that there is some process that determines when and if each individual gets the treatment via the equation below,

$$
\text { Treatment }_{i j}= \begin{cases}1 & \text { if } \eta_{j}+\eta_{x} X_{i j}+e_{i j}>0 \\ 0 & \text { otherwise. }\end{cases}
$$

A selection bias as described in the previous paragraph would arise if $\mu_{i}$ is correlated with $e_{i j}$. Examples of such potential selection correlations abound. For example, because gangs can provide collaborators for criminal ventures, those who have strong criminal tendencies (high $\mu_{i}$ ) may also be those who are more likely to join gangs (high $e_{i j}$ ). Similarly, those who have strong criminal tendencies (high $\mu_{i}$ ) may be those who are less prone toward marriage (low $e_{i j}$ ), both because such individuals may feel more constrained by marital commitments and because the traits that make them more prone toward crime make it harder for them to attract a spouse. Note that these are not simply technical issues related to estimation, but rather substantive theoretical issues regarding how the type of individuals who choose to obtain the treatment may differ from those who do not. 
The type of selection bias highlighted in the previous paragraph can be mitigated via the use of fixed-effects methods. The most basic fixed-effects estimator is almost the same as the cross-sectional regressions discussed above, but also includes individual specific dummy variables which account for each individual's "fixed-effect," or all of the unobservable individual characteristics that are constant over time that might be affecting both an individual's criminal activity and whether or not he obtains the treatment. Implicitly, this means fixed-effects estimators use the criminality of individuals who eventually get the treatment during periods when they are not receiving the treatment as the counterfactual for their own criminality in the periods in which they are.

However, for fixed-effects methods to solely identify the causal effect of a given treatment characteristic on criminality, one must also assume that there is no correlation between individual time-varying residual component of the criminal participation equation $\varepsilon_{i j}$ and the time-varying residual component of the treatment equation $e_{i j}$. This is often referred to as the "sequential ignorability condition." However, as I will argue below, this sequential ignorability condition is often untenable. To illustrate this concern more completely, it is helpful to re-write equations (3) and (4) from above as

$$
\begin{gathered}
\operatorname{Ln}\left(\lambda_{i j}\right)=\beta_{j}+\beta_{T} \text { Treatment }_{i j}+\beta_{x} X_{i j}+\left(\mu_{i}+\varphi_{i j}^{c}+\gamma_{i j}\right) \quad \text { and } \\
\text { Treatment }_{i j}= \begin{cases}1 & \text { if } \eta_{j}+\eta_{x} X_{i j}+\left(\omega_{i}+\varphi_{i j}^{T}+\gamma_{i j}\right)>0 \\
0 & \text { otherwise, }\end{cases}
\end{gathered}
$$

where the residual term in each equation is now divided into three components, the individual-fixed component ( $\mu_{i}$ in the crime equation, $\omega_{i}$ in the treatment equation), the individual time-varying component that is unique to a given process $\left(\varphi_{i j}^{c}\right.$ in the crime equation and $\varphi_{i j}^{T}$ in the treatment equation), and an individual time-varying component that potentially affects both processes $\left(\gamma_{i j}\right)$. In some senses, such individual time-varying shocks can be thought of as "turning points" that affect life trajectories (Laub and Sampson 1993). The potential existence of a turning point event that affects both criminality and a variety of other processes, or a non-negligible $\gamma_{i j}$ component, will imply that changes in the treatment dummy will still be correlated with the residual in the crime 
equation, causing estimates of the treatment effect $\beta_{T}$ to be biased. In other words, even using individual fixed-effects, estimates of the causal effect of the treatment on individual criminality will still be biased if whatever change that arises that causes an individual to obtain the treatment at a given point in time also directly affects that individual's tendency toward criminal activity at that point in time.

Again, this is not simply a technical estimation issue, but a key theoretical issue that a researcher must grapple with when using a fixed-effects methodology and has been discussed extensively in other contexts such as the impact of training programs on earnings (Ashenfelter 1978; Heckman and Smith 1999). To discuss this concern more concretely, we can again consider the treatment characteristic of gang-membership. On the one hand, the decision regarding when to initiate gang membership may be due only to changes in circumstances or attitudes that are uncorrelated with anything to do with an individual's criminality, but affect his opportunity to join or benefit from gang membership (i.e. it is changes in $\varphi^{T}{ }_{i j}$ that cause individuals to change treatment status between periods, while $\gamma_{i j}$ is negligible for all such individuals). For example, an individual's parents might move him from a relatively gang free neighborhood to a more gang dense neighborhood. If all gang initiations were thought to arise in a manner such as this, then fixed-effects methods would give unbiased estimates of the direct impact of gang membership on individual criminal activity. On the other hand, the decision to join a gang may be one facet of a broader change in behavior resulting from some unobserved change in overall attitudes or circumstances that also affect each individual's underlying tendency toward crime (i.e. $\gamma_{i j}$ is not negligible for some individuals). For example, an individual's relationship with his parents or siblings becomes strained, or the individual becomes a drug user, which cause him both to become more prone toward crime and seek out gang membership. Consequently, the higher criminality of individuals during the periods in which they are gang members may simply reflect changes in their unobserved attitudes or circumstances at the time, not the actual impact of gang membership per se on their criminal behavior.

An analogous argument can be made regarding the results with respect to marriage. Numerous theoretical arguments have been put forward arguing how the institution of marriage may directly affect an individual's criminal activity (Sampson and 
Laub 1993; Warr 1998; Giordano, Cerkovich, and Rudolph 2002). If individuals primarily become married because they finally meet "the right person," and such meetings are not related to anything affecting each individual's underlying criminality, fixed-effects estimators could be used to estimate this direct impact of being married on individual criminal activity. However, it seems very likely that for some individuals, marriage timing reflects other things beyond just meeting the right person. An individual has to feel ready for marriage, which might be part of an overall attitudinal change that it is time for them to "grow up," which certainly might impact their underlying criminality. Moreover, to get married an individual has to find a willing partner, which might be more likely for men who have already undertaken attitudinal and circumstantial changes that could also be expected to lower their underlying criminality. The extent to which timing of marriage is affected by these other more broad changes in attitudes will determine the bias of any fixed-effects estimate of the direct impact of marriage on crime.

This issue of active choice by individuals to select into certain institutions has also been directly highlighted by Hirschi and Gottfredson (1995) in talking about the estimates of the causal effects of such institutions:

"From our perspective, these apparent effects and identical findings reported in the life-course literature are a consequence of self-selection and statistical regression. Put in theoretical terms, they are straightforward consequences of the failure to take into consideration the decision-making capabilities of the individuals making up our samples. In our view, it is illegitimate to wish away the capacities of individuals to seek and find environments compatible with their wishes and desires."

\section{III - How Large Can a Dynamic Selection Bias Be?}

The above section discussed how selection biases might arise in many criminological applications. While some of such selection biases can be eradicated via the use of fixed-effects methods, the possibility of dynamic selection biases are still there. To gain some insights into the potential size of such biases, this section uses data from the NLSY97 to estimate several fixed-effects specifications of different treatments on

\footnotetext{
${ }^{2}$ Thanks to an anonymous reader for pointing this paper and selection out.
} 
individual criminality. Two of the treatments I consider, gang affiliation and marriage, have been examined previously using fixed-effects methods but with different data. As described in detail above, while both of these treatments have strong theoretical arguments for why they may directly impact criminal behavior, fixed-effects estimates may overstate such effects due to a dynamic selection bias. Therefore, I also consider estimates of a third "treatment" on individual criminality---namely cigarette smoking.

No research that I am aware of argues that smoking cigarettes can have a direct causal impact on increasing individual criminality. ${ }^{3}$ If anything, smoking cigarettes has been argued to suppress aggressive responses and behaviors (Acri and Grunberg 1992; Berston, Beattie, and Walker 1976; Cherek 981; Driscoll and Baettig 1981; Hutchingson and Emley 1973; Jamner, Shapiro, and Javik 1999; Schechter and Rand 1974; Rodgers 1979). Therefore, any positive empirical relationship between the two arguably reflects only correlation arising from some form of selection bias. Indeed, a large body of literature has shown that smoking is correlated with rebelliousness (Burt et al. 2000, Stewart and Livson 1966), experiencing traumatic events (Acierno 2000), and stress (Koval and Pederson 1999; Kassel, Paronis and Stroud 2003)---all variables that could very plausibly directly affect an individual's criminality and generally not controlled for in most studies. Moreover, numerous researchers have also shown that particular stressful or negative life events often directly precede adolescents' initiation of smoking (Wills, Sandy, and Yaeger 2002; Lloyd and Taylor 2004; Siqueira et al. 2000). Again, it is certainly possible that experiencing a stressful life event (e.g. father/mother lost job, parents divorced, failed a grade, witnessed violence) could directly alter an individual's subsequent criminal behavior trajectory.

As will be shown below, if one believes there is no causal relationship between the act of smoking and increased criminal activity, considering how the size of the estimated relationship between smoking and crime changes with different estimation methods is informative with respect to the potential bias regarding estimates of causal effects inherent in different estimators.

\footnotetext{
${ }^{3}$ Numerous papers have argued that smoking can act as a gateway drug to harder drugs (Torabi et al. 1993; Chen et al. 2002; Fleming et al. 1989). However, this claim is often supported by showing that smoking is simply correlated with a higher likelihood of harder drug use later on. Clearly, this association is subject to the critique that is the subject of this paper.
} 


\section{III(A) - Data}

The data I will use for the following analyses come from the National Longitudinal Survey of Youth 1997 (NLSY97). The NLSY97 consists of a survey of a nationally representative sample of approximately 9,000 youths who were 12 to 16 years old as of December 1996 conducted under the auspices of the Bureau of Labor Statistics. Those youth selected for the NLSY97 have been surveyed annually since 1997 regarding their labor market experiences, education, marriage and childbearing, health, drug and substance use, as well as criminal activity including gang participation. The sample I use in the analyses that follow consist of all male youth who were interviewed in each panel wave from 1997 to 2005. Moreover, I construct a five year sub-panel of these individuals, covering the survey years 2001-2005. In other words, each individual appears in my data set five separate times, each time reflecting data for that individual corresponding to a different panel year.

Of primary interest is the criminal participation data for this sample. One benefit of the NLSY97 is that the questions regarding criminal activity were asked using a selfadministered questionnaire via a laptop computer rather than through a written survey or a face-to-face interview. Given the personal nature of these questions, the increased privacy and confidentiality offered by the laptop may elicit substantially more truthful responses than many previously available from self-reported data sources. Indeed, Turner et al. (1998) provide substantial evidence that youth are much more likely to report risky personal behaviors (including sexual experiences, drug use, and violent acts) when surveyed via a self-administered audio computer interface than responding to selfadministered questions on paper. The computer interface used in the NLSY97 was very similar to self-administered audio computer interface examined by Turner et al. (1998), in that it both provided an optional audio interface (where the respondents could listen to questions using headphones), and automatically took respondents through the appropriate questioning loops. Therefore, while there certainly still may be underreporting of sensitive issues such as participation in criminal activity, the degree of such underreporting is likely to be substantially less in the NLSY97 than many previous 
surveys including the NLSY79 (which asked criminal participation questions via a selfadministered paper and pencil instrument).

In the analyses that follow, I will consider four types of crime categories: property crimes (stealing plus “other” property crimes), assault, drug sales, and total crimes. I measure the criminal participation by an individual in a given year for any of the first three categories as the number of times the individual said he committed that crime since the date of his previous NLSY97 interview. While the "number of times" an individual could admit to committing a particular crime in the previous time period is potentially open ended, I top-coded it at five for two reasons. First, some individuals admitted to an implausibly high number of criminal instances (e.g. 500) in the previous year. Including such observations may skew the results substantially. Second, and more importantly, a sizeable number of individuals would not offer specific number of instances of criminal acts, but rather would only admit to committing such acts on "three or more than times". My results are not sensitive to other top-coding values.

I then calculated total crimes for each individual by simply summing the three separate criminal activity categories. Given each individual crime category is top-coded at five acts over the course of the previous year, the total crime category is implicitly topcoded at fifteen criminal acts over the course of the previous year, with no more than five of those acts being from any given category.

\section{III(B) - Pooled Cross-Sectional Analysis}

The most basic approach to estimating the effect of a treatment variable on some outcome is simply to estimate the cross-sectional correlations between the two. Table 1 summarizes the results of several “pooled” Cross-Sectional Poisson regression specifications as specified in equations (1) and (2) above, where each individual contributes five separate observations to the estimation results, corresponding to each of the five panel years. In keeping with the two studies these results will subsequently be compared to (Gordon et al., 2004; Sampson, Laub, and Wimer, 2006), the $X_{i j}$ vector of individual characteristics consists of age, age squared, and indicator variables for panel year. Different regressions are run for each of the three "treatments" (i.e. in a gang in last year, married at time of interview, smoked cigarettes in last year) and each of different 
crime categories (i.e. total crimes, property crimes, assault, and drug sales), where each crime variable is a count of the number of times the individual said he committed such a crime since the previous time he was interviewed. The first column of Table 1 shows the dependant variable for each specification, the second column shows the coefficients on the gang status indicator variable in the gang status regressions, the third column shows the coefficients on the marital status indicator variable in the marital status regressions, and the fourth column shows the coefficients on the smoking indicator variable in the smoking status regressions (coefficients on the age variables and panel indicators are not shown in the interest of brevity).

These specifications are generally referred to as "pooled” Cross-Sectional regressions, as they pool data coming from several panel periods and do not use the panel aspects of the data---namely, as stated above, given that the data set contains data on each individual for each of the five panel years, the same individual appears five times in the overall data set. $^{4}$

As can be seen in the first column of numbers in Table 1, after controlling for age and panel year, belonging to a gang is indeed significantly correlated with higher criminality (of all types) as predicted by theory. ${ }^{5}$ Moreover, the second column of numbers reveals after controlling for age and panel year, being married is significantly correlated with a lower level of criminality, a finding also consistent with the theoretical predictions.

As discussed above, it is likely that these estimates reflect a substantial selection bias with respect to the true causal effect of either of these treatments on individual criminality. Namely, those individuals who are the type to select themselves into a gang might be very different from those who would never join a gang, and these differences, not gang participation per se, at least partly account for the higher levels of criminality among gang members than non-gang members. Similarly, those individuals who are the type to get married at some point might be very different from those who would never

\footnotetext{
${ }^{4}$ However, standard errors are clustered by individual, meaning the standard errors are adjusted for the fact that observations for the same individual are not statistically independent across panel periods. In terms of the equations above, the residual $r_{i j}$ terms are not assumed to be independent, rather they are allowed to have an arbitrary correlation within individual (but are independent across individuals).

${ }^{5}$ Gang status in a given panel year was determined by whether the respondent answered yes to the question "Have you been a member of a gang since last interviewed?"
} 
married, and these differences at least partly account for the lower levels of criminality among married men compared to unmarried men.

The third column of numbers in Table 1 gives some indication of how large this type of a selection bias can be. As can be seen, individuals who smoked cigarettes in the last year commit significantly more crimes than individuals who did not. ${ }^{6}$ However, as discussed above, this must all be due to a selection bias with respect to the treatment of smoking, or that individuals who choose to smoke have a much higher underlying propensity for crime than individuals who do not. Given the size of these estimated coefficients, one must be concerned that such selection bias might also make up a significant portion of the earlier estimates of the effects of gang participation and marriage on crime.

As a first attempt to correct for such selection biases, Table 2 shows the results of similar regressions to those summarized in Table 1, but adds an additional variable to each specification, namely "never in gang” in the specifications looking at the effect of gang participation, "never married” in the specifications looking at the effect of marriage, and "never smoked" in the specifications looking at the effect of smoking on crime. The way to interpret the coefficients shown in Table 2 is as follows. The coefficient on the never treated indicator (i.e. “never in gang”, “never married”, “never smoked”) variable reveals the degree to which those who were never "treated" (i.e. were never in a gang, never married, never smoked) differed in their criminality from the "treated" during the periods these treated individuals did not receive the treatment. The coefficient on the treatment indicator (“in gang”, “married”, “smoked”) variable reveals the degree to which those who were treated differed in their average level of criminality during the periods they actually received the treatment (e.g. were in a gang, were married, smoked in the previous year) compared to the periods they did not.

Given the above interpretation, the results in the first column of numbers in Table 2 suggest that individuals who never admitted to being a gang member over the whole sample frame committed significantly fewer crimes than those who were in a gang at least one period during the sampling frame even during the periods these individuals

\footnotetext{
${ }^{6}$ Smoking status in a given panel year was determined by whether the respondent answered yes to the question "Have you smoked a cigarette since last interviewed?"
} 
were not in the gang. Similarly, the results in the second column of numbers in Table 2 suggest that individuals who were never married over the whole sample frame committed significantly more crimes than those who were married at least one period during the sampling frame even during the periods these individuals were not married. One could certainly interpret these results as evidence of a substantial selection bias with respect to who eventually joins a gang or gets married. In terms of equations (3) and (4), these findings suggest that individuals who never belong to a gang, and therefore must have a relatively low $e_{i j}$ each period, have a lower average $\mu_{i}$ than those who at some point join a gang (and therefore who must have a relatively high $e_{i j}$ at least once). Similarly, those who never marry appear to have a higher average $\mu_{i}$ than those who at some point marry. The same holds true with respect to smoking, with those who never smoke having a lower underlying tendency toward criminality than those who at some other point in time pick up smoking. This suggests that the coefficients shown in Table 1 give a biased picture of the true causal effects of gang status and marital status (and obviously smoking) on individual criminal activity, as the untreated with respect to each of these treatments do not give a valid missing counterfactual for the treated.

Looking further at Table 2, the second column of numbers suggests that individuals who belonged to a gang sometime during the sample frame committed significantly more crimes on average in periods when they were in the gang compared periods when they were not. Similarly, the third column of numbers suggests that individuals who were married sometime during the sample frame committed significantly fewer crimes (particularly property crimes) on average in periods when they were married than when they were not. These results are essentially the motivation for using “fixed-effects” type estimators. Intuitively, fixed-effects estimators use the criminality of individuals who eventually get the treatment in the periods in which they are not treated as the counterfactual for their own criminality in the periods in which they are treated.

\section{III(C) - Basic Fixed-Effects Analyses}

As discussed above, the most basic fixed-effects estimator is almost the same as the pooled cross-sectional regressions, but also includes individual dummies to control for each individual's “fixed-effect," or the unobserved individual components that are 
constant across panel years (i.e. $\mu_{i}$ ). For more technical and complete presentations of fixed-effects estimation techniques for social science applications see Wooldridge (2002), Hausman and Taylor (1981), Winship and Morgan (1999), Hsiao (1986), and Halaby (2004).

Each column of numbers in Table 3 shows the coefficient on a specific “treatment” variable in separate fixed-effects Poisson regression specifications for each of the four different criminal participation dependant variables. ${ }^{7}$ The coefficients on the gang participation dummy variable shown in the first column of numbers reveal that even when using only the within individual variation inherent in the fixed-effects approach, criminal activity is significantly higher in periods when individuals are in a gang than those periods when they say they are not. Similarly, the coefficients in the second column of numbers in Table 3 reveal that individuals generally commit significantly fewer crimes in those periods when they are married than those periods when they are not.

Interestingly, the coefficients on the gang participation and married indicator variables in Table 3 that arise from these fixed-effects estimates are about half of the size of the analogous coefficients that arise from the pooled cross-section regressions shown in Table 1. In words, this suggests that indeed much of the strength of the relationships between gang participation and crime, and marriage and crime, are due to selection--more criminally prone individuals are more likely to join gangs and less likely to marry than less criminally prone individuals.

As discussed above, however, interpreting even these smaller in magnitude fixedeffects results as causal may still be problematic. In particular, one might be concerned that whatever change an individual is experiencing at a given point in time that causes him to join a gang or get married might also be affecting his underlying criminality. The extent to which this is true will bias the fixed-effects estimates of each treatment on criminality away from zero.

To gain some insight into how large such a bias could be, let us again consider the empirical relationship between smoking and crime. The third column of numbers in

\footnotetext{
${ }^{7}$ Technically, these estimates are called a conditional fixed-effects estimates, but will be referred to simply as a fixed-effects estimator here for brevity. Coefficients on the other included time varying regressors are also omitted for brevity. Note that the number of observations and number of persons shown at the bottom of Table 3 indicate that individuals for whom the dependant variable (i.e. crime count for each category) is zero in all panel years do not contribute to the estimates.
} 
Table 3 shows the coefficients on a dummy variable for whether the individual smoked cigarettes in a given period in fixed-effects specifications otherwise analogous to those used to obtain the coefficients in the previous two columns of Table 3. Similar to the results for gang participation and marriage, the fixed-effects coefficients with respect to smoking shown in Table 3 are substantially smaller in magnitude than the pooled crosssectional results shown in Table 1. This reveals that fixed-effects methods can be a substantial improvement over basic cross-sectional methods in diminishing selection bias. However, the fixed-effects coefficients on the smoking dummy shown in Table 3 are still substantial and statistically greater than zero at well above the $1 \%$ confidence level. Hence, even though it is unlikely that the act of smoking itself causes individuals to commit more crime, basic fixed-effects estimators are not able to rule such an effect out, and indeed would still suggest that such an effect is quite substantial. ${ }^{8}$

\section{III(D) - Pre-During-Post Fixed-Effects Analyses}

In their analysis of gang participation and crime, Gordon et al. (2004) use a slight variation on the simple fixed-effects estimator used above. Instead of using just one variable indicating whether or not an individual belonged to a gang in a particular period, they created two separate indicator variables in each period for each individual who said they were in a gang at some point during the panel---one indicating the individual did not participate in a gang in that period and that period was before his gang participation began, and the second indicating the individual did not participate in a gang in that period and that period was after his gang participation ended.

The primary motivation for this method comes from the fact that a standard fixedeffects estimator would make no distinction between any increases in criminality that occur around the time periods when an individual initiates gang membership for the first time versus any decreases in criminality that occur around the time periods when an individual chooses to desist from gang membership. Clearly, the relative magnitudes of these two potential changes in criminality do not have to be symmetric. By including two

\footnotetext{
${ }^{8}$ McKinnish (2008) has argued that fixed-effects estimators can also suffer from bias toward zero due to a type of measurement error attenuation bias in instances where the treatment in question has both transitory and longer-term components, but where only the longer-term component is expected to have a substantial impact on the outcome of interest. Given the treatments of interest here---gang participation, marriage, and smoking---this concern is relatively minor in this analysis.
} 
indicators---one indicating a period before gang participation began, and the second indicating a period was after gang participation ended---Gordon et al. (2004) hope to potentially separate out these two possibly heterogeneous effects. Moreover, by subtracting the coefficient on the first indicator from the coefficient on the second, they can also examine how criminal participation differs between the periods prior to gang involvement versus periods after gang involvement ended.

The first column of numbers in Table 4 shows the results of several fixed-effects Poisson regressions analogous to those performed by Gordon et al. (2004), but using the data from the NLSY97 described above. ${ }^{9}$ As these reported coefficients show, the biggest increase in criminal activity for individuals who report being in a gang at some point during the five panel years is during the transition from the periods prior to joining a gang and the periods while in a gang. However, the results also indicate that criminal activity for these individuals was significantly higher when in the gang compared to after leaving the gang, and somewhat higher (at least with respect to property crimes) after gang involvement desisted compared to before gang involvement started.

While the measures of criminality are quite different between the NLSY97 data used here and the measures used by Gordon et al. (2004), the results shown here compare very favorably. Specifically, the second column of numbers in Table 4 reveals that the biggest change in criminal activity (all crimes as well as each type of crime separately) occurs between pre-gang periods to during gang periods, consistent with Gordon et al's findings. Moreover, like the results in Gordon et al., the results shown in Table 4 reveal that criminal activity is also much higher when individuals are in a gang than after they quit, but it is still somewhat higher after they quit than before they became involved in the first place. ${ }^{10}$

\footnotetext{
${ }^{9}$ All specifications also include each individual's age and age squared, along with indicators for panel year. Gordon et al. (2004) actually use negative binomial regressions. Poisson regressions are used here since there is some variation in each individual's "exposure" in each panel year, as the time between interviews varied between individuals. It is more straightforward to incorporate such variable exposure in Poisson regressions. However, all results in this paper are qualitatively equivalent using negative binomial specifications as done by Gordon et al (2004).

${ }^{10}$ Moreover, if anything, gang status has a stronger connection to criminality using the NSLY97 data than the delinquency data used by Gordon et al. (2004). This likely has to do with the fact that the oldest youth in the data set used by Gordon et al. (2004) were 16, while the youth in the NLSY97 data used here range from 15 years old (the youngest cohort in the first panel year) up to 24 years old (the oldest cohort in the
} 
The second column of numbers in Table 4 presents the results of similar fixedeffect Poisson regressions, but which use marital status rather than gang status as the right-hand side treatment variable of interest. As can be seen, these specifications suggest that criminal activity falls for individuals when they are married relative to before they were married. However, these results are relatively imprecisely estimated and only significant at any standard significance level with respect to assaults. Given the fact that there are very few individuals in the NLSY97 panels used here that are divorced because of their relatively young ages during these panel years, the statistical imprecision of the estimates is even worse when it comes to evaluating the criminal behavior of those who get divorced (i.e. had periods "after” marriage), making it hard to make any meaningful inferences from these coefficients.

The third column of numbers in Table 4 shows the coefficients analogous to those described above, but again use cigarette smoking since the last interview as the "treatment" of interest. As can be seen, this pre-during-post fixed-effects analysis reveals that among individuals who smoke, these individuals commit significantly more crimes in years when they smoke than in the years prior to smoking or in years after they have ceased smoking. Once again, this means that if one were to interpret these fixed-effects results as causal, one would conclude that the act of smoking causes individuals to commit more crimes. This arguably erroneous conclusion can be dismissed only if one grants that there is some unobserved time-varying attribute such that changes in this attribute cause individuals to change their behavior with respect to both smoking and criminality contemporaneously such as a stressful or negative life event. Given such a time varying unobserved attribute exists, we clearly can’t rule out the possibility that similar such unobserved changes also affect individuals' decisions regarding whether or not to get married (or divorced) and whether or not to join a gang (or quit a gang).

\section{III(E) - Inverse-Probability of Treatment Analyses}

Sampson, Laub, and Wimer (2006) employ a novel technique of InverseProbability of Treatment Weighting (IPTW) in their analysis of the effect of marriage on

2005 panel). Given criminality generally rises during these ages, it should not necessarily be unexpected to find a stronger association between gang status and criminality in this data set covering a larger age range. 
crime. The most basic way in which an IPTW method could be used to potentially overcome this missing counterfactual problem and correctly estimate the effect of a given treatment in a non-randomized control study is the following. First, the researcher estimates the likelihood that each individual in the data set receives the treatment history he actually received at each point in time based on his or her observable characteristics at that point in time. Then, the researcher essentially uses the inverse of these likelihoods as weights for calculating the weighted mean outcome for those who actually received the treatment, as well as the weighted mean outcome for those who did not. Under some assumptions discussed in more detail below, the difference between these weighted means can potentially give a much more accurate picture of the actual effect of the treatment than simply comparing unweighted means.

The IPTW method has most frequently been used in the medical treatment literature. ${ }^{11}$ The intuition for why this method can be helpful for estimating treatment effects can be best understood by considering the following medical example. Suppose a researcher wanted to determine the effect of a new heart medicine on heart attack occurrences. However, the researcher was not able to run a randomized treatment and control study. Therefore, if the researcher were to just compare heart attack rates between those who were prescribed the drug and another group of individuals who were not prescribed the drug, the researcher might get a biased picture of the treatment effect because those not prescribed the drug are not likely to be a valid counterfactual group for those who were. In particular, the drug was likely prescribed to those whose characteristics that made them far more at-risk of a heart attack than those who were not prescribed the drug (e.g. overweight, smoked, had a history of heart problems).

By using Inverse Probability of Treatment Weights, the researcher essentially downweights those who were empirically very likely to have received the treatment history they actually received based on their observables and upweights those who were empirically unlikely to have had the treatment history they actually received based on their observables, thereby making the treated and untreated groups more comparable in terms of the distribution of these other observables correlated with receiving the

\footnotetext{
${ }^{11}$ See Hernan, Brumback, and Robins (2000) and Robins, Hernan, and Brumback (2000) for particular examples.
} 
treatment. The underlying intuition then being that among those whose characteristics make them unlikely recipients of the drug, the reasons some got the drug and others didn't were completely random in the sense that they had nothing to do with anything directly related to heart health. For example, among the relatively healthier patients, some had doctors prone to prescribing such medicines while others didn’t. Similarly, among those whose characteristics make them likely recipients of the drug, the reasons some got the drug and others didn't were also random in the sense that they were uncorrelated with anything affecting heart health. Given these assumptions, when calculating the treatment effect via comparison of IPT Weighted means for the treated and the untreated, the researcher is better able to assign a causal interpretation to any differences in group means due to the drug, since the weighting essentially makes the treated and untreated samples more comparable in the sense that they should have similar expected heart attack rates in the absence of the drug.

In their study of the effects of marriage on crime, Sampson, Laub, and Wimer (2006) use IPT weighting within the context of a hierarchical linear equation model, where the first level is an individual in given year, and the second level is the individual overall. ${ }^{12}$ Specifically, they employ the following empirical model, which is almost identical to that laid out in equations above. Namely, they estimate a within-person model:

$$
\begin{aligned}
& E\left(\text { crimes }_{i j}\right)=\eta_{i j} * \lambda_{i j} \\
& \operatorname{Ln}\left(\lambda_{i j}\right)=\beta_{0, i}+\beta_{1} \text { Treatment }_{i j}+r_{i j},
\end{aligned}
$$

where their Treatment variable equals one if an individual $i$ is married at time period $j$, and the initial between-person component of the model takes the following form:

$$
\beta_{0, i}=\alpha+\mu_{i}
$$

\footnotetext{
12 This Hierarchical Linear Model method was introduced by Bryk and Raudenbush (1992) and has been used in a very similar context to this (but without IPTW weights) by Horney, Osgood, and Marshall (1995).
} 
While this HLM method differs only slightly from the more standard fixed-effects regressions discussed above, the key difference is that Sampson, Laub, and Wimer (2006) compute Inverse Probability of Treatment Weights with respect to marriage for each person in each year using both time invariant and time varying individual characteristics, and then estimate the system of equations shown above using these period specific individual IPT weights. ${ }^{13}$

To create the IPT weights, Sampson, Laub, and Wimer estimate the likelihood of marriage for each person in each panel year using a logistic regression of a dummy variable indicating whether or not an individual is married during a given panel year on a variety of individual characteristics, family and parental characteristics, and adult timevarying characteristics. A complete list of the variables they employ is shown in the first column of Table 5.

I have attempted to replicate Sampson, Laub, and Wimer's methods and results using the NLSY97 data. Given Sampson, Laub, and Wimer use a different data set than the NLSY97 data used here, I am not able to use the exact same individual characteristics that they use to compute IPTW weights. However, the NLSY97 contains many variables that are arguably quite similar to those used by Sampson, Laub, and Wimer. The variables I use as right-hand side variables in the logistic regressions to compute IPT weights are shown in the second column of Table 5.

The first column of numbers in Table 6 shows the estimated coefficients on the marriage dummy variables (i.e. the coefficients on the Treatment dummy) in the Hierarchical Linear Equation models for each different crime category, both from the unweighted specifications and weighted specifications using IPT weights. As can be seen, for all crime categories, the coefficients on the marriage treatment dummy are negative and statistically significant in all specifications. Interestingly, the coefficients are also always larger in magnitude when using the IPT weights than without. The second column of numbers shows the event rate ratio associated with these estimates (which can be interpreted as the ratio of per period crimes individuals commit while married versus while unmarried).

\footnotetext{
${ }^{13}$ Hierarchcial Linear Modeling software (HLM 6.0) must be used to estimate this empirical model when period specific individual weights are used, as standard fixed-effects estimation routines require individuals to have the same weight in each panel year.
} 
In general, these results using the NLSY97 data are even stronger than the results found by Sampson, Laub, and Wimer using similar methods but different data. The differences are likely due to the different years in which the data was collected (1940s1960s for the data used by Sampson, Laub, and Wimer, versus the early 2000s for the NSLY97 sample used here) and the different ages of respondents (17 to 32 year olds and 17 to 70 year olds in the data used by Sampson, Laub, and Wimer, versus 16 to 25 year olds for the NLYS97 sample used here). Given criminal activity has generally risen since the 1950s, and the fact that youths generally commit more crimes than adults, it is not necessarily surprising that the NLSY97 data leads to an even stronger empirical relationship between marriage and crime than that found by Sampson, Laub, and Wimer.

The middle two columns of numbers in Table 6 show the results of analogous estimates for the relationship between gang membership and crime. Again, results are shown for both unweighted and IPT weighted specifications. Not surprisingly, these results again show a strong relationship between gang membership and crime, with individuals committing substantially more crimes during periods when they are in gangs than in periods when they are not. Moreover, the estimated relationship is even stronger when IPT weights are used than when they are not.

The key question is whether the IPTW method used in this context can make us any more confident in interpreting the estimated effects as causal than the other more basic individual fixed-effects methods discussed above. In the context of estimating the effect of marriage on crime, Sampson, Laub, and Wimer motivate their IPTW method as follows:

“...(M)arried men who have a high probability of being married at any given age based on their marital, criminal, employment, military, and childbearing history would effectively be 'downweighted' in the IPTW analysis for that year. Such person-periods reflect a higher degree of 'selection' into the observed treatment status given values on confounding covariate histories that make them especially likely to be married (or unmarried). As a result, we do not want them to contribute as much information to the estimation of the causal effect of marriage on crime. On the other hand, married men with low probabilities of being married (but who 
actually marry) at a given age provide more useful information, and are therefore 'upweighted' when estimating the final causal effect.”

However, Sampson, Laub, and Wimer mention in a footnote following the above quote that for this method to actually be capable of capturing the true treatment effect of marriage on crime it still requires the assumption of "sequential ignorability and randomization or that marriage propensity does not depend on unobservables after accounting for observed covariates, prior treatment history, and outcomes---the thought experiment is that marriage is randomized within levels of prior variables for each person.” More specifically, like any fixed-effects estimation technique, one must assume that whatever the changes are that induce an individual to obtain the treatment (i.e. marriage) at a given point in time have no direct effect on his underlying propensity to commit crime at that point in time. In other words, one must assume there is no dynamic selection. As discussed above, this assumption may be problematic with respect to marriage and crime (and gang status and crime).

The remaining question then is whether IPT weights lessen or exacerbate any dynamic selection bias? To answer this question it is again crucial to think very closely about the processes through which individuals obtain the treatment of interest and whether these processes may differ between those who have a high likelihood of obtaining the treatment at any given point in time based on their other observable characteristics, and those who do not. In particular, if one believes that the changes that induce individuals to obtain the treatment at a given point in time are more generally orthogonal to any concurrent changes in criminal propensity for those with a low likelihood of obtaining the treatment at any point in time than for those with a high likelihood, then IPT weighting will indeed lessen the dynamic selection bias of fixedeffects estimates. However, if one believes the opposite is true, then IPT weighting will exacerbate the dynamic selection bias of fixed-effects estimates.

The difficulty is that there is no one empirical test that will reveal which of the above beliefs is true in any given situation. Rather, the argument for which is likely to be true must be made intuitively and theoretically. Consider marriage. What would prompt an individual whose observables suggest a high likelihood of getting married at a point in 
time to actually get married? The high empirical likelihood of marriage at a given point in time means that such an individual already has many of the characteristics of responsibility and adulthood (e.g. steady employment, a weak criminal history, perhaps already in a cohabiting relationship). Therefore, it actually seems reasonable to think that a very small event or change in attitudes could trigger a marriage decision for these men, and moreover such changes could very plausibly have nothing to do with changes in their underlying criminal propensity. On the other hand, for individuals with a low empirical likelihood of marriage at any given point in time, it is likely that reasonably large events or changes in attitudes must occur for them to enter into a marriage, and it is less clear that such large events or changes in attitudes would not also affect these individuals’ underlying criminal propensities. Hence, it is actually quite plausible that the sequential ignorability assumption is more problematic for the low likelihood of marriage men than the high likelihood of marriage men, meaning IPT weighting will increase the dynamic selection bias with respect to fixed-effects estimates of the direct effect of marriage on individual criminality. Once again, a similar argument could be made with respect to gang-status and crime.

To look at this issue in another way, let us again consider fixed-effects estimates of the relationship between smoking and crime. As discussed previously, all of this relationship is arguably due to dynamic selection bias. Moreover, like with respect to marriage, one can think that very small changes in circumstances or attitudes may induce those with a high empirical likelihood of smoking to actually take up smoking any given period, such as a small change in cigarette prices or a change in a friend's smoking behavior. Such small changes could potentially be unrelated to any changes in these individual's underlying criminal propensity. Alternatively, relatively large changes in attitudes or circumstances must occur for those with a low empirical likelihood of smoking to actually pick up smoking at a given point in time. For example, such an individual may decide he wants to rebel, or is all of a sudden is facing some stressful events. I would argue that it is unlikely that these larger attitudinal or circumstantial changes would not also affect these individuals underlying criminal propensities.

The above argument suggests that IPT weights will exacerbate the dynamic selection bias when it comes to estimating the direct effect of smoking on criminal 
activity (which arguably should be negligible). The final two columns in Table 6 reveal this to be true. In particular, these columns show the results of analogous Hierarchical Poisson Models to those done for marriage and gang affiliation, but for smoking cigarettes. Consistent with the basic fixed-effects estimates from before, individuals seem to commit significantly more crime in periods when they smoke than in periods when they do not. Most notably however, the estimated relationship between cigarette smoking and crime is substantially stronger when the IPT weights are used than in the basic fixedeffects specification. Given that any empirical relationship between cigarette smoking and criminal activity is not likely to be causal, the fact that this relationship is stronger when using the IPT weights than without reveals the potential pitfalls of using such a method.

\section{IV - Discussion and Conclusions}

This paper is meant to highlight the importance of clearly considering and modeling the process through which individuals obtain a given treatment when one wishes to estimate the direct causal effect of the treatment on individual criminality. As shown above, such considerations are of primary importance when it comes to whether fixed-effects estimates plausibly identify only the causal effect, or also reflect a bias from a dynamic selection process. Moreover, when employing a fixed-effects estimator, authors must include a thorough discussion of the underlying assumptions with respect to the nature of the randomness in the treatment process in order for readers to assess the plausibility of the resulting estimates as capturing only causal effects.

One reasonable critique of the results shown above is that the specifications were quite simple in the sense that they included very few time-varying regressors. Including a wide array of attributes, especially time-varying attributes, can potentially mitigate much of the dynamic selection bias. However, it is rare that researchers would have access to valid and accurate measures of things like changes in maturity, changes in self-control, or

other life shocks such as parental divorce, school problems, or stressful interactions with neighbors. Moreover, there would also be the danger of over-specifying, or including as regressors things that are products of the treatment effect in question. For example, if a researcher did have data on each individuals' changes in maturity or changes in other 
behavior associated with maturity, it may still not be appropriate to include these in a fixed-effects regression of crime on marriage, since marriage may affect maturity and other associated behaviors through the same theoretical mechanisms by which it may affect crime. This will bias results toward zero. Therefore, while fixed-effects estimators are a useful tool and can be a way to control for some of the observed heterogeneity between treated and untreated groups that cross-sectional methods cannot, given that the potential of dynamic selection bias is generally very difficult if not impossible to completely rule out, interpreting fixed-effects results as causal must be done with substantial caution.

I would argue that one very effective use for fixed-effects methods is to show how cross-sectional correlations between a given treatment characteristic and individual criminality may reflect selection rather than a truly causal relationship. For example, Nagin and Farrington used fixed-effects methods to show that the positive association between past and future criminal behavior (1992a), as well as the negative association between onset of criminal behavior and persistent offending (1992b), are both almost exclusively driven by time-stable individual differences, or in other words, these relationships are the result of selection, not causality. Similarly, Grogger (1995) uses individual fixed-effects methods to show that while men who were arrested make substantially less than men who were not, most of this correlation is due to "unobserved characteristics that jointly influence crime and labor market behavior, rather than from the causal effects of arrests.”

Admittedly, this more limited usage of these methods drastically curtails criminological researchers' ability for getting well-identified estimates of causal relationships in many important contexts. The obvious alternative is for researchers to look for natural experiments, regression discontinuities, and other types of exogenous instruments to identify the causal effects of various endogenous treatments on criminality. In terms of the equations above, researchers can look for shocks that affect equation (4') but do not directly enter equation (3'). For example, welfare reform changed the penalties associated with being married for low income women, which in turn may have affected men's opportunities for marriage, but had no direct effect on the payoffs to crime. Moreover, such reforms happened somewhat differently and at different 
times in different states, meaning some men were affected in different ways and at different times than others. One could then potentially use these arguably exogenous sources variation in individual's propensity to marry to estimate the direct effect of marriage on crime. Or, researchers could potentially identify the direct effect of gang participation on criminality by comparing the changes in criminality for individuals whose gang affiliation was broken because they had to move to a different but otherwise comparable neighborhood due to changes in public housing policy or availability, to the changes in criminality for individuals who did not have to move and whose gang affiliation stayed constant over the same time period.

One particular recent example of a criminological study that uses an identification strategy in this vein is Apel et al. (2009). In particular, Apel et al. are interested in identifying the causal effect of youth employment on delinquency. Like the examples discussed in this paper, the concern is that the treatment of "being employed" is a choice made by the individual, and hence there is substantial concern regarding selection into who gets the treatment, as well as when individuals choose to get the treatment. To overcome these concerns, Apel et al. use variation in child labor laws across states as a source of plausibly exogenous differences between youth that affect their likelihood of employment at any given point in time but are not directly correlated with any individual youth’s underlying criminality at any given point in time.

While the estimates that come from such natural experiments and instrumental variable methods can often provide vary plausible estimates of causal effects, they are also not without drawbacks. Often the identified treatment effects may be relevant only to very specific groups and not necessarily representative of the U.S. population (and therefore such estimates are often referred to as Local Average Treatment Effects) (Imbens and Angrist 1994). Moreover, the instruments or natural experiments may be only weakly correlated with the treatment of interest, which may lead to substantial understatements or very imprecise estimates. Moreover, for many treatments of interest, it may be extremely hard or impossible to find instruments and natural experiments that are both correlated with the treatment of interest and truly exogenous to the criminological outcome of interest. 
However, one positive development inherent in the natural experiments and instrumental variables literature has been for authors to provide a very focused discussion of the intuition and the underlying processes that are being used for identification of the treatment effect parameter of interest. This paper suggests that a similar emphasis on and discussion of underlying processes should be a crucial part of fixed-effects analyses. 


\section{V - References}

Ashenfelter, Orley. (1978). "Estimating the Effect of Training Programs on Earnings.” Review of Economics and Statistics 60: 47-57.

Acierno, Ron, Dean G. Kilpatrick, Heidi Resnick, Benjamin Saunders, Michael De Arellano, and Connie Best. (2000). “Assault, PTSD, Family Substance Use, and Depression as Risk Factors for Cigarette Use in Youth: Findings from the National Survey of Adolescents.” Journal of Traumatic Stress 13(3): 381-396.

Acri, J.B. and N.E. Grunberg. (1992). “A Psychophysical Task to Quantify Smoking Cessation-induced Irritability: The Reactive Irritability Scale (RIS).” Addictive Behaviors 17: 587-601.

Apel, Robert, Shawn Bushway, Ray Paternoster, Robert Brame, and Gary Sweeten. (2009). "Using State Child Labor Laws to Identify the Causal Effect of Youth Employment on Deviant Behavior and Academic Achievement.” Journal of Quantitative Criminology (forthcoming).

Berntson, G.G., M.S. Beattie, and J.M. Walker. (1976). "Effects of Nicotinic and Muscarinic Compounds on Biting Attack in the Cat.” Pharmacology, Biochemistry and Behavior 5: 235-239.

Bloklund, Arjan A.J. and Paul Nieuwbeerta. (2005). "The Effects of Life Circumstances on Longitudinal Trajectories of Offending.” Criminology 43: 1203-240.

Bushway, Shawn, Robert Brame, and Ray Paternoster. (1999). “Assessing Stability and Change in Criminal Offending: A Comparison of Random Effects, Semiparametric, and Fixed Effects Modeling Strategies.” Journal of Quantitative Criminology 15(1): 23-61. 
Burt, Richard D., Khanh T. Dinh, Arthur V. Peterson Jr., and Irwin G. Sarason. (2000).

"Predicting Adolescent Smoking: A Prospective Study of Personality Variables." Preventative Medicine 30: 115-125.

Bryk, Anthony S. and Stephan W. Raudenbush. (1992). Hierarchical Linear Models: Application and Data Analysis Methods. Newbury Park, CA: Sage.

Chaiken JM, and MR Chaiken. (1990). "Drugs and Predatory Crime.” in Drugs and Crime ed. Micheal Tonry and James Q. Wilson. Chicago, IL: University of Chicago Press.

Chen, Xinguang, Jennifer B. Unger, Paula Palmer, Michelle C. Weiner, Carl Anderson Johnson, Mamie M. Wong, and Greg Austin. (2002). "Prior Cigarette Smoking Initiation Predicting Current Alcohol Use: Evidence for a Gateway Drug Effect Among California Adolescents from Eleven Ethnic Groups.” Addictive Behaviors 27(5): 799-817.

Cherek, D. R. (1981). "Effects of Smoking Different Doses of Nicotine on Human Aggressive Behavior.” Psychopharmacology 75: 339-345.

Driscoll, P. and K. Baettig. (1981). "Selective Inhibition by Nicotine of Shock-Induced Fighting in the Rat.” Pharmacology, Biochemistry and Behavior 14: 175-179.

Farrington, David P. (1988). "Studying Changes Within Individuals: The Causes of Offending." in Studies of Psychosocial Risk: The Power of Longitudinal Data ed. M. Ruter. New York: Cambridge University Press.

Farrington, David P., Bernard Gallagher, Lynda Morley, Raymond J.St. Ledger, and Donald J. West. (1986). “Unemployment, School Leaving, and Crime.” British Journal of Criminology 26: 335-56. 
Farrington, David P. and Donald P. West. (1995). "Effects of Marriage, Separation, and Children on Offending by Adult Males." in Current Perspectives on Aging and the Life Cycle, Volume 4: Delinquency and Disrepute in the Life Course, eds. Zena Smith Blau and John Hagan. Greenwich, CT: JAI Press.

Fleming, Raymond, Howard Leventhal, Kathleen Glynn, and Joan Ershler. (1989). “The Role of Cigarettes in the Initiation and Progression of Early Substance Use.” Addictive Behaviors 14: 261-272.

Furgusson, David M., Nicola R. Swain-Campell, and L. John Horwood. (2000). "Deviant Peer Affiliations, Crime and Substance Use: A Fixed Effects Regression Analysis.” Journal of Abnormal Child Psychology: August.

French, Micheal T., Kerry Anne McGeary, Dale Chitwood, Clyde B. McCoy, James A. Inciardi, and Duane McBride. (2000). “Chronic Drug Use and Crime”. Substance Abuse 21(2): 95-109.

Giordano, Peggy C., Stephen A. Cernkovich, and Jennifer L. Rudolph. (2002). "Gender Crime, and Desistance: Toward a Theory of Cognitive Transformation.” American Journal of Sociology 107: 990 - 1064.

Gordon, Rachel A., Benjamin B. Lahey, Eriko Kawai, Rolf Loeber, Magda StouthamerLoeber, David Farrington. (2004). “Anti-Social Behavior and Youth Gang Membership: Selection and Socialization.” Criminology 42(1): 55-87.

Grogger, Jeffrey. (1995). "The Effects of Arrests on the Employment and Earnings of Young Men.” The Quarterly Journal of Economics 110(1): 51-71.

Halaby, Charles N. (2004). "Panel Models in Sociological Research: Theory into Practice.” Annual Review of Sociology 30: 507-544. 
Hausman, Jerry and W. Taylor. (1981). “Panel Data and Unobervable Individual Effects.” Econometrica 49: 1377-1398.

Haynie, Dana L., Peggy C. Giordano, Wendy D. Manning, Monica A. Longmore. (2005). “Adolescent Romantic Relationships and Delinquency Involvement.” Criminology 43(1): 177-210.

Heckman, James J. and Jeffrey A. Smith. (1999). “The Pre-Programme Earnings Dip and the Determinants of Participation in a Social Programme. Implications for Simple Programme Evaluation Strategies.” The Economic Journal 109: 313-348.

Hernan, Miguel Angel, Babette Brumback, and James M. Robins. (2000). “”Marginal Structural Models to Estimate the Causal Effect of Zidovudine on the Survival of HIVPositive Men.” Epidemiology 11: 561-70.

Hirschi, Travis and Michael Gottfredson. (1995). "Control Theory and the Life-Course Perspective.” Studies on Crime and Crime Prevention 4(2): 131-142.

Hoffman, John P. and Jiangmin Xu. (2002). “School Activities, Community Service, and Delinquency.” Crime \& Delinquency 48: 568-591.

Horney, Julie, D. Wayne Osgood, and Ineke Haen Marshall. (1995). “Criminal Careers in the Short-term: Intra-Individual Variability in Crime and Its Relation to Local Life Circumstances.” American Sociological Review 60: 655-673.

Hutchinson, R.R. and G.B. Emley. (1973). “Effects of Nicotine on Avoidance, Conditioned Suppression and Aggression Response Measures in Animals and Man.” in W.L. Dunn (ed.) Smoking Behavior: Motives and Incentives, Washington DC: Winston.

Hsiao, Cheng. (1986). “Chapter 3: Simple regression with variable intercepts.” Analysis of Panel Data. Cambridge UK: University of Cambridge Press. 
Imbens, Guido and Joshua Angrist. (1994). “Identification and Estimation of Local Average Treatment Effects.” Econometrica 62(2): 467-475.

Jamner, L.D., D. Shapiro, and M.E. Jarvik. (1999). "Nicotine Reduces the Frequency of Anger Reports in Smokers and Nonsmokers with High but not Low Hostility: An Ambulatory Study.” Experimental and Clinical Psychopharmacology 7: 454-463.

Kassel, Jon D., Carol A. Paronis, and Laura R. Stoud. (2003). “Smoking, Stress, and Negative Affect: Correlation, Causation, and Context Across Stages of Smoking.” Psychological Bulletin 129(2): 270-304.

Koval, John J. and Linda L. Pederson. (1999). "Stress-Coping and Other Psychosocial Risk Factors: A Model for Smoking in Grade 6 Students.” Addictive Behaviors 24(2): 207-218.

Laub, John H. and Robert J. Sampson. (1993). “Turning Points in the Life Course: Why Change Matters to the Study of Crime.” Criminology 31: 301-25.

Lloyd, Donald and John Taylor. (2004). "Stress as a Distal Predictor of Heavy Smoking Initiation in Young People.” Paper presented at the Annual Meeting of the American Sociological Association.

McKinnish, Terra. (2008). "Panel Data Models and Transitory Fluctuations in the Explanatory Variable.” in Advances in Econometrics Vol. 21.

Osgood, DW, JK Wilson, PM O’Malley, JG Bachman, LD Johnston. (1996). “Routine Activities and Individual Deviant Behavior.” American Sociological Review 61: 635-55.

Robins, James M., Miguel Angel Hernan, and Babette Brumback. (2000). “Marginal Structural Models and Causal Inference in Epidemiology.” Epidemiology 11(5): 550-560. 
Rodgers, R.J. (1979). “Effects of Nicotine, Mecamylamine, and Hexamethonium on Shock-Induced Fighting, Pain Reactivity, and Locomotor Behavior in Rats.” Psychopharmacology 66: 93-98.

Sampson, Robert J. and John H. Laub. (1990). “Crime and Deviance over the Life Course: The Salience of Adult Social Bonds.” American Sociological Review 55: 609-27.

----. (1993). Crime in the Making: Pathways and Turning Points through Life. Cambridge, MA: Harvard University Press.

Sampson, Robert J., John H. Laub, and Christopher Wimer. (2006). “Does Marriage Reduce Crime? A Counterfactual Approach to Within-Individual Causal Effects.” Criminology 44(3): 465-108.

Schechter, M.D. and M.J. Rand. (1974). "Effects of Acute Deprivation of Smoking on Aggression and Hostility.” Psychopharmacologia 35: 19-28.

Siqueira, Lorena, Marguerite Diab, Carol Bodian, and Linda Rolnitzky. (2000). “Adolescents Becoming Smokers: The Roles of Stress and Coping Methods.” Journal of Adolescent Health 2000(27): 399-408.

Solon, Gary. (1989). “The Value of Panel Data in Economic Research.” in Panel Surveys, eds. Daniel Kasprzyk, Greg Duncan, Graham Kalton, and M.P. Singh. New York, NY: John Wiley \& Sons. pp. 486-496.

Stewart, Louis and Norman Livson. (1966). “Smoking and Rebelliousness: A Longitudinal Study from Childhood to Maturity.” Journal of Consulting Psychology 30(3): 225-229.

Stolzenberg, Lisa and Stewart J. D’Alessio. (2007). “The Effect of Divorce on Domestic Crime.” Crime \& Delinquency 53: 281-302. 
Torabi, M., W.J. Bailey, and M. Maid-Jabbari. (1993). “Cigarette Smoking as a Predictor of Alcohol and Other Drug Use by Children and Adolescents: Evidence of the "Gateway Drug’ Effect.” Journal of School Health 63(7): 302-06.

Turner C.F., L. Kim, S.M. Rogers, L.D. Lindberg, J.H. Pleck, and F.L. Sonenstein. (1998). “Adolescent Sexual Behavior, Drug Use, and Violence: Increased Reporting with Computer Survey Technology.” Science 280: 867-873.

Warr, Mark. (1998). “Life-course Transitions and Desistance from Crime.” Criminology 36: 183-216.

Wills, Thomas A., James M. Sandy, and Alison M. Yaeger. (2002). "Stress and Smoking in Adolescence: A Test of Directional Hypotheses.” Health Psychology 21(2): 122-130.

Winship, Christopher and Stephen L. Morgan. (1999). “The Estimation of Causal Effects from Observational Data.” Annual Review of Sociology 25: 659-706.

Wooldridge, Jeffrey M. (2002). Econometric Analysis of Cross Section and Panel Data. Cambridge MA: MIT Press. 
Table 1 - Pooled Cross-Sectional Poisson Regression Model Results

\begin{tabular}{|c|c|c|c|}
\hline \multirow[b]{2}{*}{$\begin{array}{l}\text { Dependant } \\
\text { Variable }\end{array}$} & \multicolumn{3}{|c|}{$\begin{array}{c}\text { Individual Characteristic Variable of Interest } \\
\text { (i.e. "Treatment") }\end{array}$} \\
\hline & $\begin{array}{c}\text { In Gang } \\
\text { Coefficient } \\
\text { (SE) }\end{array}$ & $\begin{array}{c}\text { Married } \\
\text { Coefficient } \\
\text { (SE) } \\
\end{array}$ & $\begin{array}{c}\text { Smoked } \\
\text { Coefficient } \\
(\mathrm{SE}) \\
\end{array}$ \\
\hline Total Crimes & $\begin{array}{c}2.383 \\
(0.095)^{\star \star \star}\end{array}$ & $\begin{array}{l}-1.120 \\
(0.201)^{\star \star \star}\end{array}$ & $\begin{array}{c}1.518 \\
(0.089)^{\star \star \star}\end{array}$ \\
\hline Property Crimes & $\begin{array}{c}2.933 \\
(0.143)^{\star \star \star}\end{array}$ & $\begin{array}{l}-1.450 \\
(0.340)^{\star \star \star}\end{array}$ & $\begin{array}{c}1.464 \\
(0.146)^{\star \star \star}\end{array}$ \\
\hline Assaults & $\begin{array}{c}2.628 \\
(0.106)^{\star \star \star}\end{array}$ & $\begin{array}{l}-0.790 \\
(0.310)^{\star \star}\end{array}$ & $\begin{array}{c}1.123 \\
(0.107)^{\star \star \star}\end{array}$ \\
\hline Drug Sales & $\begin{array}{c}1.811 \\
(0.121)^{\star \star \star}\end{array}$ & $\begin{array}{l}-1.197 \\
(0.298)^{\star \star \star}\end{array}$ & $\begin{array}{c}1.818 \\
(0.120)^{\star \star \star}\end{array}$ \\
\hline $\begin{array}{l}\text { Observations }=12 \\
\text { Data comes from } \\
\text { From this data, } 2 \\
\text { includes each ind } \\
\text { White Robust Sta } \\
\text { significance at } 10 \\
\text { level. }\end{array}$ & $\begin{array}{l}\text { is }=2,896 \text {. E } \\
d \text { includes all } \\
\text { nels are crea } \\
\text { (in months), } \\
\text { clusetered b } \\
\text { dicates signif }\end{array}$ & $\begin{array}{l}\text { comes from } \\
\text { lid data for ea } \\
\text { or this analysi } \\
\text { and panel ind } \\
\text { shown in pa } \\
\text { evel, and }\end{array}$ & $\begin{array}{l}\text { specification. } \\
\text { om 1997-2005. } \\
\text { oecification also } \\
\text { mies. Huber- } \\
\text { * indicates } \\
\text { ignificance at } 1 \%\end{array}$ \\
\hline
\end{tabular}


Table 2 - Pooled Cross-Sectional Poission Regression Model Results

Individual Characteristic Variable of Interest

(i.e. "Treatment")

\begin{tabular}{|c|c|c|c|c|c|c|}
\hline \multirow[b]{2}{*}{$\begin{array}{l}\text { Dependant } \\
\text { Variable } \\
\end{array}$} & \\
\hline & $\begin{array}{c}\text { Never in Gang } \\
\text { Coefficient } \\
\text { (SE) } \\
\end{array}$ & $\begin{array}{c}\text { In Gang } \\
\text { Coefficient } \\
\text { (SE) } \\
\end{array}$ & $\begin{array}{c}\text { Never Married } \\
\text { Coefficient } \\
\text { (SE) } \\
\end{array}$ & $\begin{array}{c}\text { Married } \\
\text { Coefficient } \\
(\mathrm{SE}) \\
\end{array}$ & $\begin{array}{c}\text { Never Smoked } \\
\text { Coefficient } \\
\text { (SE) } \\
\end{array}$ & $\begin{array}{c}\text { Smoked } \\
\text { Coefficient } \\
\text { (SE) } \\
\end{array}$ \\
\hline Total Crimes & $\begin{array}{c}-1.137 \\
(0.135)^{\star \star \star}\end{array}$ & $\begin{array}{c}1.330 \\
(0.136)^{\star \star \star}\end{array}$ & $\begin{array}{c}0.499 \\
(0.185)^{\star \star \star}\end{array}$ & $\begin{array}{c}-0.651 \\
(0.245)^{\star \star \star}\end{array}$ & $\begin{array}{c}-0.949 \\
(0.157)^{\star \star \star}\end{array}$ & $\begin{array}{c}0.994 \\
(0.109)^{\star \star \star}\end{array}$ \\
\hline Property Crimes & $\begin{array}{c}-1.594 \\
(0.199)^{\star \star \star}\end{array}$ & $\begin{array}{c}1.492 \\
(0.196)^{\star \star \star}\end{array}$ & $\begin{array}{c}0.443 \\
(0.282)\end{array}$ & $\begin{array}{c}-1.032 \\
(0.400)^{\star \star \star}\end{array}$ & $\begin{array}{c}-1.136 \\
(0.248)^{\star \star \star}\end{array}$ & $\begin{array}{c}0.867 \\
(0.178)^{\star \star \star}\end{array}$ \\
\hline Assaults & $\begin{array}{c}-1.546 \\
(0.154)^{\star \star \star}\end{array}$ & $\begin{array}{c}1.225 \\
(0.158)^{\star \star \star}\end{array}$ & $\begin{array}{c}0.378 \\
(0.210)^{\star}\end{array}$ & $\begin{array}{l}-0.437 \\
(0.366)\end{array}$ & $\begin{array}{c}-0.626 \\
(0.188)^{\star \star \star}\end{array}$ & $\begin{array}{c}0.752 \\
(0.133)^{\star \star \star}\end{array}$ \\
\hline Drug Sales & $\begin{array}{c}-0.567 \\
(0.168)^{\star \star \star}\end{array}$ & $\begin{array}{c}1.275 \\
(0.172)^{\star \star \star}\end{array}$ & $\begin{array}{c}0.602 \\
(0.235)^{\star \star}\end{array}$ & $\begin{array}{c}-0.630 \\
(0.324)^{\star}\end{array}$ & $\begin{array}{c}-1.140 \\
(0.236)^{\star \star \star}\end{array}$ & $\begin{array}{c}1.214 \\
(0.138)^{\star \star \star}\end{array}$ \\
\hline
\end{tabular}

Observations $=14,480$. Persons $=2,896$. Data comes from NLSY97, and includes all males with valid data for each year from 1997-2005. From this data, 2001-2005 panels are created and used for this analysis. Each specification also includes each individual's age (in months), age squared, and dummy indicators of panel wave. Huber-White Robust standard errors clustered by individual are shown in parenthases. * indicates significance at $10 \%$ level, $* *$ indicates significance at $5 \%$ level, and ${ }^{\star * \star}$ indicates significance at $1 \%$ level. 
Table 3 - Fixed-Effects Poisson Regression Model Results

\begin{tabular}{|c|c|c|c|}
\hline \multirow[b]{2}{*}{$\begin{array}{l}\text { Dependant } \\
\text { Variable }\end{array}$} & \multicolumn{3}{|c|}{$\begin{array}{c}\text { Individual Characteristic Variable of Interest } \\
\text { (i.e. "Treatment") }\end{array}$} \\
\hline & $\begin{array}{c}\text { In Gang } \\
\text { Coefficient } \\
\text { (SE) }\end{array}$ & $\begin{array}{c}\text { Married } \\
\text { Coefficient } \\
\text { (SE) } \\
\end{array}$ & $\begin{array}{c}\text { Smoke Cigarettes } \\
\text { Coefficient } \\
\text { (SE) }\end{array}$ \\
\hline Total Crimes & $\begin{array}{c}1.366 \\
(0.054)^{\star \star \star}\end{array}$ & $\begin{array}{c}-0.613 \\
(0.141)^{\star \star \star}\end{array}$ & $\begin{array}{c}0.659 \\
(0.046)^{\star \star \star}\end{array}$ \\
\hline Property Crimes & $\begin{array}{c}1.760 \\
(0.092)^{\star \star \star}\end{array}$ & $\begin{array}{l}-1.039 \\
(0.311)^{\star \star \star}\end{array}$ & $\begin{array}{c}0.698 \\
(0.087)^{\star \star \star}\end{array}$ \\
\hline Assaults & $\begin{array}{c}1.133 \\
(0.092)^{\star \star \star}\end{array}$ & $\begin{array}{c}-0.621 \\
(0.258)^{\star \star}\end{array}$ & $\begin{array}{c}0.626 \\
(0.085)^{\star \star \star}\end{array}$ \\
\hline Drug Sales & $\begin{array}{c}1.186 \\
(0.098)^{\star \star \star}\end{array}$ & $\begin{array}{c}-0.399 \\
(0.202)^{\star \star}\end{array}$ & $\begin{array}{c}0.665 \\
(0.070)^{\star \star \star}\end{array}$ \\
\hline
\end{tabular}

For the specifcations with "Total Crimes" as the dependant variable, observations $=4,405$, persons $=881$. For the specifcations with "Property Crimes" as the dependant variable, observations $=1,730$, persons $=346$. For the specifcations with "Assaults" as the dependant variable, observations = 2,660 , persons $=532$. For the specifcations with "Drug Sales" as the dependant variable, observations $=2,380$, persons $=476$. Data comes from NLSY97, and includes all males with valid data for each year. from 1997-2005. From this data, 2001-2005 panels are created and used for this analysis. Each specification also includes each individual's age (in months), age squared, and dummy indicators of panel wave. * indicates significance at $10 \%$ level, ** indicates significance at $5 \%$ level, and ${ }^{\star \star \star}$ indicates significance at $1 \%$ level. 
Table 4 - Fixed-Effects Poisson Regression Model Results

Individual Characteristic Variable of Interest

(i.e. "Treatment")

\begin{tabular}{|c|c|c|c|}
\hline $\begin{array}{l}\text { Dependant } \\
\text { Variable } \\
\end{array}$ & $\begin{array}{c}\text { In Gang } \\
\text { Difference in } \\
\text { Coefficients } \\
\text { (SE) }\end{array}$ & $\begin{array}{c}\text { Married } \\
\text { Difference in } \\
\text { Coefficients } \\
\text { (SE) }\end{array}$ & $\begin{array}{c}\text { Smoke Cigarettes } \\
\text { Difference in } \\
\text { Coefficients } \\
\text { (SE) }\end{array}$ \\
\hline \multicolumn{4}{|l|}{ Total Crimes } \\
\hline during vs. before & $\begin{array}{c}1.715 \\
(0.088)^{\star \star \star}\end{array}$ & $\begin{array}{l}-0.307 \\
(0.243)\end{array}$ & $\begin{array}{c}0.460 \\
(0.069)^{\star \star \star}\end{array}$ \\
\hline during vs. after & $\begin{array}{c}1.089 \\
(0.074)^{\star \star \star}\end{array}$ & $\begin{array}{l}15.597 \\
(908.4)\end{array}$ & $\begin{array}{c}0.805 \\
(0.061)^{\star \star \star}\end{array}$ \\
\hline after vs. before & $\begin{array}{c}0.627 \\
(0.121)^{\star \star \star}\end{array}$ & $\begin{array}{r}-15.904 \\
(908.4)\end{array}$ & $\begin{array}{c}-0.345 \\
(0.091)^{\star \star \star}\end{array}$ \\
\hline \multirow{2}{*}{$\begin{array}{l}\text { Property Crimes } \\
\text { during vs. before }\end{array}$} & 2.503 & -0.174 & 0.500 \\
\hline & $(0.158)^{\star \star \star}$ & $(0.513)$ & $(0.132)^{\star \star \star}$ \\
\hline during vs. after & $\begin{array}{c}1.133 \\
(0.127)^{\star \star \star}\end{array}$ & $\begin{array}{c}14.524 \\
(2201.8)\end{array}$ & $\begin{array}{c}0.839 \\
(0.117)^{\star \star \star}\end{array}$ \\
\hline after vs. before & $\begin{array}{c}1.370 \\
(0.0 .214)^{\star \star \star}\end{array}$ & $\begin{array}{l}-14.698 \\
(2201.8)\end{array}$ & $\begin{array}{c}-0.339 \\
(0.175)^{\star}\end{array}$ \\
\hline \multicolumn{4}{|l|}{ Assaults } \\
\hline during vs. before & $\begin{array}{c}1.319 \\
(0.148)^{\star \star \star}\end{array}$ & $\begin{array}{c}-1.183 \\
(0.502)^{\star \star}\end{array}$ & $\begin{array}{c}0.405 \\
(0.123)^{\star \star \star}\end{array}$ \\
\hline during vs. after & $\begin{array}{c}1.025 \\
(0.124)^{\star \star \star}\end{array}$ & $\begin{array}{c}15.517 \\
(1091.9)\end{array}$ & $\begin{array}{c}0.797 \\
(0.116)^{\star \star \star}\end{array}$ \\
\hline after vs. before & $\begin{array}{c}0.293 \\
(0.199)\end{array}$ & $\begin{array}{l}-16.700 \\
(1091.9)\end{array}$ & $\begin{array}{c}-0.391 \\
(0.165)^{\star *}\end{array}$ \\
\hline \multicolumn{4}{|l|}{ Drug Sales } \\
\hline during vs. before & $\begin{array}{c}1.328 \\
(0.161)^{\star \star \star}\end{array}$ & $\begin{array}{l}-0.057 \\
(0.365)\end{array}$ & $\begin{array}{c}0.493 \\
(0.110)^{\star \star \star}\end{array}$ \\
\hline during vs. after & $\begin{array}{c}1.106 \\
(0.0 .139)^{\star \star \star}\end{array}$ & $\begin{array}{l}14.804 \\
(921.9)\end{array}$ & $\begin{array}{c}0.775 \\
(0.090)^{\star \star \star}\end{array}$ \\
\hline after vs. before & $\begin{array}{c}0.222 \\
(0.0 .227)\end{array}$ & $\begin{array}{l}-14.861 \\
(921.9)\end{array}$ & $\begin{array}{c}-0.282 \\
(0.140)^{\star \star}\end{array}$ \\
\hline
\end{tabular}

Data comes from NLSY97, and includes all males with valid data for each year from 1997-2005. From this data, 2001-2005 panels are created and used for this analysis. Each specification also includes each individual's age (in months), age squared, and dummy indicators of study wave. * indicates significance at $10 \%$ level, ** indicates significance at $5 \%$ level, and ${ }^{\star \star \star}$ indicates significance at $1 \%$ level. 
Table 5 - Variables Used in First Stage Logistic Regressions for Calculating IPTW weights.

\begin{tabular}{|c|c|}
\hline Sampson, Laub, and Wimer (2006) & This paper \\
\hline Measured IQ & AFQT Score (Armed Forces Qualification Test) \\
\hline Competence & Mother gave birth as a teenager \\
\hline Delinquent Behavior & Lived with both biological parents at age 12 \\
\hline Age at first arrest & Region of residence at age 12 \\
\hline Days incarcerated up to age 17 & Home broken into prior to the age of 12 \\
\hline Extroversion & Saw a shooting prior to the age of 12 \\
\hline Adventourousness & Ratio of Family Income to Poverty Level \\
\hline Egocentricity & Number of moves before age of 12 \\
\hline Aggressiveness & Mother's highest grade \\
\hline Stubbornness & Mother's supervision style "authoritarian: \\
\hline Family Poverty & Mother's supervision style "uninvolved" \\
\hline Residential Mobility & Immigrant Status \\
\hline Parental Education & Household members under 18 \\
\hline Mother's Supervision & Family faced "hardtimes" while respondent was young \\
\hline Immigrant Status & Number of arrests in previous person-period \\
\hline Family Size & Number of assualts committed in previous person-period \\
\hline Erratic-threatening Discipline & Cumulative sum of assults up to last person-period \\
\hline Family Disruption & Any property crimes committed in previous person-period \\
\hline Criminality-Alcoholism of Parents & Cumulative sum of property crimes committed \\
\hline Mental Disorder of Parents & up to last person-period \\
\hline Married in last person-period & Any drug sales committed in previous person-period \\
\hline $\begin{array}{l}\text { Cumulative Sum of Years married } \\
\text { up to last person period }\end{array}$ & $\begin{array}{l}\text { Cumulative sum of drug sales committed } \\
\text { up to last person-period }\end{array}$ \\
\hline Any arrest in last person-period & Took drugs in last person-period \\
\hline Cumulative Sum of criminal events & Cumulative sum of previous person-periods took drugs \\
\hline Days incarcerated up to last person-period & In gang in previous person-period \\
\hline Cumulative Sum of days incarcerated & Cumulative sum of previous person-periods in gang. \\
\hline In Military in last person-period & Smoked cigarettes in previous person-period \\
\hline Cumulative sum of in military person-periods & Cumulative sum of previous person-periods smoked \\
\hline Had a child in the last person-period & Married in previous person-period \\
\hline Cumulative sum of number of children in household & Cohabited in previous person-period \\
\hline Steady employment in last person-period & Cumulative sum of previous person-periods cohabitating \\
\hline Cumulative sum of steady employment person-periods & Employed in previous person-period \\
\hline Lagged pooled violent crime count & Cumulative sum of previous person-periods employed \\
\hline Lagged pooled property crime count & In military in previous person-period \\
\hline Lagged pooled drug crime count & Cumulative sum of previous person-periods in miliatary \\
\hline Stable cohabiting relationship in previous person-period & Age \\
\hline Cumulative sum of steady cohab relationship & Age squared \\
\hline Age & Race \\
\hline Age squared & Panel year dummies \\
\hline
\end{tabular}


Table 6 - Hierarchical Variable Exposure Poisson Models (Unweighted and IPTW Weighted)

\begin{tabular}{|c|c|c|c|c|c|c|}
\hline \multirow[b]{3}{*}{$\begin{array}{l}\text { Dependant } \\
\text { Variable } \\
\end{array}$} & \multicolumn{6}{|c|}{ Individual Characteristic Variable of Interest (i.e. "Treament") } \\
\hline & \multicolumn{2}{|r|}{ Married } & \multicolumn{2}{|r|}{ In Gang } & \multicolumn{2}{|c|}{ Smoke Cigarettes } \\
\hline & $\begin{array}{c}\text { Coefficient } \\
\text { (SE) }\end{array}$ & $\begin{array}{c}\text { Event Rate Ratio } \\
\text { (95\% Confidence Int.) }\end{array}$ & $\begin{array}{c}\text { Coefficient } \\
\text { (SE) }\end{array}$ & $\begin{array}{c}\text { Event Rate Ratio } \\
\text { (95\% Confidence Int.) }\end{array}$ & $\begin{array}{c}\text { Coefficient } \\
\text { (SE) }\end{array}$ & $\begin{array}{c}\text { Event Rate Ratio } \\
\text { (95\% Confidence Int.) }\end{array}$ \\
\hline Total Crimes & $\begin{array}{c}-1.112 \\
(0.116)^{\star \star \star}\end{array}$ & $\begin{array}{c}0.329 \\
(0.262,0.413)\end{array}$ & $\begin{array}{c}1.335 \\
(0.277)^{\star \star \star}\end{array}$ & $\begin{array}{c}3.802 \\
(2.209,6.542)\end{array}$ & $\begin{array}{c}0.876 \\
(0.085)^{\star \star \star}\end{array}$ & $\begin{array}{c}2.402 \\
(2.035,2.836)\end{array}$ \\
\hline $\begin{array}{l}\text { Total Crimes } \\
\text { (IPTW weighting) }\end{array}$ & $\begin{array}{c}-1.406 \\
(0.198)^{\star \star \star}\end{array}$ & $\begin{array}{c}0.245 \\
(0.166,0.362)\end{array}$ & $\begin{array}{c}2.397 \\
(0.094)^{\star \star \star}\end{array}$ & $\begin{array}{c}10.985 \\
(9.128,13.220)\end{array}$ & $\begin{array}{c}1.487 \\
(0.089)^{\star \star \star}\end{array}$ & $\begin{array}{c}4.423 \\
(3.716,5.265)\end{array}$ \\
\hline Property Crimes & $\begin{array}{l}-1.496 \\
(0.155)^{\star \star \star}\end{array}$ & $\begin{array}{c}0.224 \\
(0.165,0.303)\end{array}$ & $\begin{array}{c}1.997 \\
(0.393)^{\star \star \star}\end{array}$ & $\begin{array}{c}7.365 \\
(3.412,15.896)\end{array}$ & $\begin{array}{c}1.072 \\
(0.113)^{\star \star \star}\end{array}$ & $\begin{array}{c}2.921 \\
(2.340,3.646)\end{array}$ \\
\hline $\begin{array}{l}\text { Property Crimes } \\
\text { (IPTW weighting) }\end{array}$ & $\begin{array}{c}-1.766 \\
(0.335)^{\star \star \star}\end{array}$ & $\begin{array}{c}0.171 \\
(0.089,0.330)\end{array}$ & $\begin{array}{c}2.96 \\
(0.143)^{\star \star \star}\end{array}$ & $\begin{array}{c}19.283 \\
(14.563,25.534)\end{array}$ & $\begin{array}{c}1.420 \\
(0.148)^{\star \star \star}\end{array}$ & $\begin{array}{c}4.136 \\
(3.096,5.526)\end{array}$ \\
\hline Assaults & $\begin{array}{l}-1.00 \\
(0.186)^{\star \star \star}\end{array}$ & $\begin{array}{c}0.367 \\
(0.255,0.529)\end{array}$ & $\begin{array}{c}1.566 \\
(0.278)^{\star \star \star}\end{array}$ & $\begin{array}{c}4.787 \\
(2.779,8.248)\end{array}$ & $\begin{array}{c}0.880 \\
(0.074)^{\star \star \star}\end{array}$ & $\begin{array}{c}2.411 \\
(2.083,2.789)\end{array}$ \\
\hline $\begin{array}{l}\text { Assaults } \\
\text { (IPTW weighting) }\end{array}$ & $\begin{array}{c}-1.101 \\
(0.306)^{\star \star \star}\end{array}$ & $\begin{array}{c}0.333 \\
(0.183,0.606)\end{array}$ & $\begin{array}{c}2.635 \\
(0.105)^{\star \star \star}\end{array}$ & $\begin{array}{c}13.939 \\
(11.342,17.130)\end{array}$ & $\begin{array}{c}1.094 \\
(0.107)^{\star \star \star}\end{array}$ & $\begin{array}{c}2.988 \\
(2.424,3.682)\end{array}$ \\
\hline Drug Sales & $\begin{array}{c}-1.130 \\
(0.125)^{\star \star \star}\end{array}$ & $\begin{array}{c}0.323 \\
(0.253,0.413)\end{array}$ & $\begin{array}{c}1.242 \\
(0.155)^{\star \star \star}\end{array}$ & $\begin{array}{c}3.464 \\
(2.556,4.693)\end{array}$ & $\begin{array}{c}1.097 \\
(0.078)^{\star \star \star}\end{array}$ & $\begin{array}{c}2.995 \\
(2.571,3.489)\end{array}$ \\
\hline $\begin{array}{l}\text { Drug Sales } \\
\text { (IPTW weighting) }\end{array}$ & $\begin{array}{c}-1.455 \\
(0.291)^{\star \star \star}\end{array}$ & $\begin{array}{c}0.233 \\
(0.132,0.413)\end{array}$ & $\begin{array}{c}1.827 \\
(0.120)^{\star \star \star}\end{array}$ & $\begin{array}{c}6.212 \\
(4.906,7.866)\end{array}$ & $\begin{array}{c}1.792 \\
(0.119)^{\star \star \star}\end{array}$ & $\begin{array}{c}6.004 \\
(4.757,7.578)\end{array}$ \\
\hline Dat & able & tes signific & 0 le & ates significe & lev & $\begin{array}{l}\mathrm{a}, 2001-2005 \mathrm{p} \\
\text { treatment" indi } \\
\star \star \text { indicates }\end{array}$ \\
\hline
\end{tabular}

